\title{
Fenâ'nın Dilinden Adem'i Okumak
}

\author{
Reading "Adem" in The Language of "Fenâ"
}

\begin{abstract}
Özet
Edebî eserler incelenirken mensubu olunan medeniyetin dünya görüşü, değerler çerçevesi, kavram ve anlam dünyası dikkate alınmadığı takdirde; edibin ve döneminin eksik veya yanlı̧̧ anlaşılması kaçınılmazdır. Âkif Paşa (17871845)'nın Adem Kasidesi'ndeki "adem" ifadesiyle şekillenen şiirin dünyası, şiirin ruhuna uygun bir biçimde "fena" kavramı ve çağrışımları ile yeniden okunduğunda, elde edilemeyen varlığa bir isyan yerine; varlığın örttüğü, perdelediği ve gizlediği fena (yokluk, yok olma) halinin ve neticede yaşanan sıkıntıların sebep ve sonuçları görülecektir. Bunu anlatmak isteyen şair hemen ilk beyitte (Yokluk düşüncesinin bile insana can verdiğine, yokluk şarabının özünün canın cevheri olduğuna) dikkat çeker ve akabinde, (Yokluğun cennet bahçesindeki nimetlerle kiyaslanamaz) olduğunu vurgularken "fena" halinin özelliklerine dikkat çekmektedir. Şiirin son beytinde ise şair kendini (İki cihânın şahlar şahının yolunda yok olduğunu) söylerken, bir manada fenâ-fi'r-resûl haline işaret etmiş olmaktadır. Bu sebeple Adem Kasidesi'nin şairin mensup olduğu medeniyetin diliyle yeniden okunması faydalı olacaktır, düşüncesindeyiz.
\end{abstract}

Ali PULAT

Anahtar Kelimeler: Adem Kasidesi, fena, şiir

\begin{abstract}
Absract
When literary works are studied, unless worldview of its civilization, the frame of value, concept and meaning world are considered, it is indispensable that the poet and his period will be misunderstood. When the world of the poem shaped by phrase "Adem" in Adem Paşa's (1787-1845) Adem Kaside is re-read with the concept of "fena" (absence) and its associations in accordance to its spirit, the condition of fena (absence, to be absent) in which the entity covers, conceals and hides and the causes and reasons and results of the distresses will be seen (without the revolt against the creator). In the first stanza, poet draws attention to that "the thought of absence gives life to humans "and "the essence of absence wine is the core of soul". Then, as he emphasizes that the blessings of Eden cannot be compared with "Absence", he pays attention to the features of the case of "fena". In the last stanza, when the poet tells that "he disappeared for the sake of the king of the kings". In a way he emphasizes the situation of "fenâ-fi'rresûl". Therefore, it will be more beneficial If Adem Kaside is re-read by the language of the civilization it belongs.
\end{abstract}

Keywords: Adem Kasidesi, absence, poem. 
Âlâyiş-i dünyâdan el çekmeğe niyet var

Yakında adem dirler bir şehre azîmet var

Bâkî

\section{Giriş}

Adem Kasidesi’nin zihniyet ve şekil yönünden eski şiirin bir devamı olduğu, şairin (aslında her insanın) maddî alemde yaşadıklarının ve gördüklerinin hikemî sırlarla adeta örtüldüğü, bu manevî dünyanın kendini hemen ele vermediği ve kolayca anlaşılamayacağı bilinen bir durumdur. İç içe geçmiş çok boyutlu bu dünyanın sınırlarını ve özelliklerini kesin yargilarla dile getirmek işin özünde bu hikemî zihniyete çok da uymaz. Bu çerçevede Adem Kasidesi’ne hikemî tarzın bir ürünü kabul edip yaklaşmak konu ile ilgili pek çok muamma gibi görünen meselenin halline sebep olacaktır, kanaatindeyiz.

Tasavvufî literatürde fenâ kavramı kulun Allah'ın bekâsı karşısında kendini yok bilmesi ve böylece gerçek kulluğa ulaşması (Kara,1995:333) demektir. Fenâ hâlini yaşayan sûfi Cüneyd-i Bağdadîye göre saflık, sükûn ve teslimiyet hâlindedir; Hasan Harakânîye göre sûfî, kendisini Allah'la beraber hissettiğinde vefâ hâlini, Allah'ın kendisiyle beraber olduğunu bildiğinde de fenâ hâlini yaşamaktadır (Kara,1995:334).

Ziya Paşa Terkîb-i Bendinde fenâ kavramını "çeşme-i pür-hûn-1 fenâ" (Parlatır,1988:359) ifadesi ile kullanır. Aşk şarabını içerek mest olan klasik şair yerini, "yokluk kanıyla dolu çeşmeden" içmek zorunda kalan şaire bırakmıştır. Ziya Paşa'ya göre, yokluk kanıyla dolu çeşmeden bir katre içen, bu dünyanın belâsından kurtulamayacaktır. Şairin düşüncesine göre fenâ halini yaşayan kimsenin imtihanı ağırdır. Bu sebeple gökten yağmur yerine inci yağsa bahtsız olanın bağına bir tanesi bile düşmez.

Hikmet, medeniyetimizin bir kavramı olarak, batı merkezli felsefî yaklaşımdan farklı yönüyle daha çok Kur'an ve sünnet kaynaklı tasavvufî anlamda "derin kavrayış ve bilgi, nübüvvet, sır ve öğüt” (Yorulmaz, 1996:14) gibi tefekkür merkezli bir anlayışla tanımlanmıştır. Bilgelik anlamında ele alınan "hikmet" varlı̆̆ın gerçeğinin bilgisi, Allah'ın tüm varlığı yaratı̧̧ gayesi, varlığın hakikatini bilip ona göre hayırlı işler yapılması, İslâmî ve tasavvufî özlü söz gibi anlamlarda (Çetin,2012:153) kullanılmıştır. Adem Kasidesi, hikmetin esas alındığı bir zihniyetin tezahürüdür; bu çerçevede bunalım, ikilem ve isyan gibi felsefî bakış açılarıyla değil, sabır, tevekkül, hikmet ve marifet kavramlarıyla değerlendirildiğinde şiirin dünyasına vukûfiyetin artacağ 1 görülecektir.

Mehmet Kaplan şiirin tahlilinde, Âkif Paşa'nın adem fikrinin mutasavvıflarınkine çok yaklaşıı̆ıını, adem fikrinin ıztırap vâkıası ile yakından ilgili olduğunu ifade eder ve 
metafiziği psikolojiye bağlar, İslâm kültüründeki fikirleri sadece tekrarladığını, bu konuda orijinal olamadığını söyler (Kaplan,1985:22). Mehmet Kaplan’ın görüşüne göre, gelgitler yaşayan Âkif Paşa'nın arada kalmışlığı ve yeni şeyler söyleyememiş olması aslında eski dünyamızın son buluşunun bir tezahürüdür.

Ahmet Hamdi Tanpınar, Âkif Paşa'yı eskinin devamı görür, Adem Kasidesi'ni de Mr. Gibb'in meşhur bir İngiliz şiirine kıyasla “Bedbinlerin Marsaillaise'i” olarak nitelendirir. Şiiri dil, hayal, mazmun ve skolastik(!) bilginin hayallerde oynadığg1 rol yönleriyle eski estetiğe bağlı olduğunu belirtir (Tanpınar,1985:95).

Müsteşrik Gibb, Adem Kasidesi’ni “bütün Türk edebiyatının en dehşetli şiiri” diye nitelemiş, ardından Âkif Paşa'yı da "hayat fikrinden nefret ediyor" şeklinde değerlendirmiştir. Gibb, Adem Kasidesi'nde Akif Paşa'nın bu dünyaya katlanamadığını düşünür, hatta Akif Paşa için “cennette kudsîlerin varlı̆̆ının bıkkınlık...” (Gibb'den Akt. Kolcu,2008:19) sebebi olduğunu söyler. Gibb’e göre Akif Paşa, mutlak huzuru mutlak yoklukta aramaktadir.

Oysa, yüzyılların birikimi ve medeniyetimizin değer anlayışına göre mutlak huzur, Mutlak Varlık'ta yok olmaktır. Akif Paşa, bu şiirde geleneksel anlayışımız çerçevesinde hayatı ve sonsuz âlemi ele almış, yaşanan sıkıntılara da ârifâne bir yaklaşımla çözüm bulmaya çalışmıştır, kanaatindeyiz.

\section{Kasideyi Fenânın Dilinden Okumak}

Hasan Akay, bu şiirde adem imgeleriyle örülen büyük bir “Adem”in olduğundan bahseder. Akay, şiirdeki ize ulaşmak için varlığın, şairin hayatının ve şairin aslını yok etmediğinin ispatı hükmünde, ademe ve adem'dekine bakmak gerektiğini vurgular. Akay yazısında, yokluk gibi soyut ve negatif bir kavrama kaside yazmanın bir yenilik olduğunu ifade ettikten sonra "adem"in ne olabileceğine dair sorular sorar. Farklı ve zengin okumalara elverişli söz konusu metnin daha iyi anlaşılması için şu soruları sorar:

“Acaba "Kasîde-i Adem”deki “adem”, yokluk mudur, hiçlik mi; Nirvana’ya ulaşmak mı, nefsin arzularından uzaklaşarak ruh kesilmek, âdeta ruhlaşmak mı; mutlak sessizliğe ermek mi -Nietzsche'nin dediği anlamda- "taş kesilmek” mi; varlığın gölgesine sığınıp yan kesilmek mi; varlık veya var oluşu toptan yokluğa mahkum etmek ya da bir çeşit intihar etmek mi? “Ölüm'ün görüntüsü mü, gölgesi mi, nefesi mi, sesi mi? Varoluşçuluk bağlamında yorumlanması gereken bir kör düğüm mü? Yoksa, varlı̆̆ın unutuluşa terk edilmesi ya da bir şekilde kurban edilmesi mi? Bütün bu sorulara tek tek "hayır", ama hepsine birden "evet" denilebilir mi? Metinde yeterince "açık" saklı değil mi? "Adem'in bizzat kendisi, metnin bıraktığı “öz”el açık olarak değerlendirilemez mi?” 
Hasan Akay, bu girift sorulara cevap olarak; “adem”in bizzat kendinin öz olduğunu ve ancak bu "öz"ün "öte” sine geçebilen okuyucunun şiirin dünyasına girebileceğini belirtir (Akay,2014).

Adem Kasidesi’ne hikemî bir değerlendirmeyle bakılırsa, âlemşümul bir zihniyeti görebiliriz. Her insanın, her dönemde ve her halde yaşadı̆̆ı, sonsuza ulaşma arzusu karşımıza çıkar. Sınırlı maddenin insanın içindeki derin ilâhî tarafı ihâta edememesi, insanın gönlünün geçici olanla tatmin olmayacağı, sonsuz aşk duygusu ile açılımlar yaşayabilecek insanın ruh dünyasının, kuru bir dünya davası ile sükûna eremeyeceği fikri bu şiirde yüzyılların birikimiyle hissettirilmeye çalış1lmıştır, diyebiliriz.

Şiirdeki önemli kavramlara tasavvufî anlamlar yüklendiğinde kasidenin bir bütün olarak ilâhî aşkın pek çok merhalesini işlediği görülecektir. Dünyevî bir bakışın tezahürü olarak "adem" yokluğu ifade ediyor zannedilebilir. Oysa şiirin tamamında Mutlak Varlık karşısındaki "adem” ele alınmış, sonsuz hayata nispetle bu dünyanın imtihan sırrını içinde barındırdığı için pek çok zorluğu yaşatacağı üzerinde durulmuştur.

\section{Cân verir âdeme endişe-i sahbâ-yı adem \\ Cevher-i cân mi aceb cevher-i minâ-yı adem}

İlk mısradaki “endişe-i sahbâ-yı adem” (Allah'ta yok olma, O’na ulaşma isteği, fikri veya niyeti) "âdeme can verir" (İnsana hayat verir, insanı canlandırır, insanın âdem olmasını sağlar, manen ölü olan kalbi ihya eder..) şeklinde ele alınırsa şiirin son beytine kadar bu tarz hikemî anlayışla kasidenin yazıldığı görülecektir.

\section{Çeşm-i îmân ile baktıkça vücûd-1 ademe}

Sahn-1 cennet görünür âdeme sahrâ-yı adem

İkinci beyite göre "vücûd-ı ademe" (fenânın varlığına) iman gözüyle bakıldığında insana fenâ âlemi, cennet gibi görünür. Üçüncü beyitte ise şair, cennet gibi görünme gibi ifadesini galat sayar; yokluk ülkesinin sükûnu başkadır, hiçbir nimete benzemez..

Şiir, sekinci beyte kadar ademin (fenâ halini yaşamanın) yüceliğinin hiçbir nimetle karşılaştırılamayacağından, bâbâ-yı adem'in âlemi sürekli beslediğinden, her tür varlığın kaynağının fenâyı temennâ etmek olduğundan, her tür varlığın yaşandığı dünyada ademin aranamayacağından bahisle; mutlak varlık karşısında hiçliğin boyutlarını hissettirmeye çalı̧̧ır.

\section{Yok dedikçe var olur yok mu garâbet bunda}

Nâm-1 hestî mi nedir hall-i muammâ-yı adem

Şair sekizinci beyitte "Yok dedikçe var olur, bunda bir gariplik yok mu?" derken, buradaki “yok” kavramını Mutlak Varlık'a nispetle bu dünyadaki geçici varlıklara işaret eder. Fâni olanın yokluğu fark edildikçe Bâkî olan kendini gösterir, Sonsuzluk anlaş1lır, demektir. Bu durum kelime-i tevhit sırrıdır; burada hiçbir ilah yoktur ancak Allah 
vardır, manası akla gelmektedir. Yokluk bilmecesinin çözümü varlığın adında gizlenmiştir. Varlığın hakikatini çözen sonsuzluğu bilir. Necip Fazıl İ̧̧aret (Kısakürek,2019:29) şiirinde benzer ruh halini şöyle ifade etmiştir:

\section{Var olan yoklukların ömrünü sürüyorum! Aşklar bomboş kuruntu, hürriyetler esaret! \\ Yalnız "Rakip" ismiyle Allah'i görüyorum! \\ Bir yokluk ki, bu dünya, var olandan işaret...}

Dokuzuncu beyitten itibaren fenâ ehlinin soyut, dile gelmez halleri somutlaştırılmaya çalışılmıştır. Adem deryası bir coşsa iki cihan fenâ dalgalarına gark olur, demek olumsuz, kötü bir hal demek değildir. Aksine burada coşma, vecd ve aşk halinin tasviri vardır. Kendi varlığından sıyrılan âşı̆̆ın bir "ah" tüm cihanı kaplar. Şair buraya kadar ademi hep insanın erebileceği en yüce mertebe en büyük nimet olarak aldığına göre burada nefret olmamalıdır. Daha sonraki beyitlerde de şair, ademi yaşama hâlinin bu dünyada görülecek en büyük nimet olduğundan bahsedecektir.

Onuncu beyitte, dünyadaki her varlığın ortaya çıkma sebebini sonsuz âlemdeki karşılığına bağlama inancı görülür. Bu dünyada ortaya çıkmış, yaşanmış(imtihan sırrı) hiçbir şey yoktur ki yarın sorulmasın ve karşımıza çıkmasın, denilmektedir. On birinci beyitte terbiyeye olan ihtiyaç, insanın ortaya çıkmasından itibaren imtihanın başlaması gündeme gelir.

Kaside on dört ve on beşinci beyitlerde varlık ve yokluk meselesinin farklı yönlerini işledikten sonra on altıncı beyitte medresenin, on yedinci beyitte de tekkenin "ademin ihfâsının manası”nı anlayamadığını ifade eder. Çünkü bu davanın yüceliği kâinâta sığmaz. Şair şeklen sonsuzluğu murat edenlerin yaptıkları yanlı̧̧ ve kusurları sosyal bir eleştiri mahiyetinde dile getirmekten çekinmez.

\section{Şeyh efendi sana der miydi ki varından geç \\ Varlı̆̆ın olmasa da sidre-i mévâ-yı adem}

Yirmi beşinci beyite göre, mecâzî manada "sidre-i me'vâ-yı adem" (yokluk yurdunun sidresi) makamına ulaşmış sâlik, hâlen fenâfillaha ulaşamadığı için şeyh efendinin varlığından vazgeç telkinine muhataptır. Sidre, Mirac yolculuğunda Cebrail'in Peygamber Efendimize refakatinin son durağılır. Cebrail oradan bir adım öteye gidemez. Adem yolculuğundaki sâlik bu makamlara gelmiş olsa bile fenâya hâlen ulaşamadığ1 için şeyhin yol göstericiliğine muhtaçtır, denilmektedir. Yirmi altıncı beyitte de sahih meşâyihin himmeti ve müridin gayreti ile ademin manası bilinir, hükmü karşımıza çıkar. Bu sebeple manevî hediyeleri alanın dünyalık beklemesinin çok anlamı olamaz, denilmiştir. Sıkıntı ve musîbetlere sabretmek, kulun imtihanını geçmesi demektir. 
Kasidenin hikmet eksenli ele alınmasına delil teşkil eden önemli bir beyit de otuz dördüncü beyittir. "Ber-murad olmayacak ben yere geçsin âlem" mısrasında geçen "bermurad” kavramı şiirin buraya kadar gelen ruhuna uygun olarak heves ve hevâ olarak değil, Allah'ın muradını murad bilme anlayı̧̧ı ile tanımlanırsa uygun olur. Fenâ hâlinin bu derece güzel ve vazgeçilmez oluşunu anlatan şairin muradı nefsânî olmamalıdır. Dolayısıyla bu imtihan dünyasında tüm varlık bizi fenâya götürmeyecekse her mahluk(yaratılmış) ârif nezdinde zaten yok olmuş demektir.

Şair otuz beşinci beyitten itibaren vecd halindedir. Kendini bu yolda feda eden kişi, her tür mihneti hoş görür. Onu sadece öteler mutmain eder.

Manevî seyr hâlinin inceliklerini, yaşananların hikmetli sırlarını anlatan Âkif Paşa şiirin sonlarına doğru (64. beyit) şiiriyle ne yapmak isteğini söylemeye çalışır.

\section{Arifân yokluk ile etmede isbât-ı vücûd \\ Ben ise varlık ile eyledim inşâ-yı adem}

Ârifânın nefis terbiyesi ile yaşadıklarını şiir dili ile anlatmak kendini övmekten çok bir özür beyanı şeklinde düşünülebilir. Çünkü varlığın her türlüsünün hakikate perde olma ihtimali vardır.

Şiirin ruhunu en iyi yansıtan beyitlerden biri yirmi sekizinci beyittir. İnsana belâ yükü olarak kendisi, kendi varlığı veya varlık zannettikleri yeter derken, insanın kendi eliyle "yarattıkları" vazgeçilmez kabul ettikleri, kendisini ilgilendirmeyen veya zararı dokunacak unsurları gereksizce yüklendiği ve onun altında ezildiği vurgusu beyitte vardır. Oysa Allah insana kaldıramayacağı yükü yüklemez. İnsanın belâ olan yükü (bâr-1 belâ) hırsları, isyanı ve gafletidir. Berayâ-yı ademde (fenâ halkında) bu yükler görülmez.

\section{Mahv-1 hâk-i reh-i şâhenşeh-i kevneynim ben Ne tevellâ-yı vïcûd u ne teberrâ-yı adem}

Şair şiirin son beytinde, manen içinde bulunduğu yeri şöyle belirler; ne varlığa (tevallâ-yı vücûd) ne de fenâya (teberrâ-yı adem) yakın olabilmiştir. Zaten maneviyat yolunda kimse ben fenâya ulaştım diyemeyeceğine göre, şair varlıktan tarafa da değilim ama iki dünyanın şahlar şahının toprağında mahvolmaya tâlibim, der. Bu yaklaşım da tasavvuf kültüründe edebe uygun bir tavırdır.

\section{Sonuç}

Adem Kasidesi hikmet esaslı okunduğunda bir insanın manevî halini, yaşadıkları karşısındaki durum ve tutumunu, imtihan sırlarının merhalelerini, sonsuzluğa gidiş yolundaki seyrini ve tecrübelerini ele alırken, yüzyılların birikimini devrin farklı anlayışlarına cevap niteliğinde sunmuş bir şiirdir. 
Adem Kasidesi dünyadaki hiçbir varlı̆̆ın sonsuzlukla kıyas edilemeyeceğini, "Bunca varlık var iken gitmez gönül yorgunluğu” düşüncesi çerçevesinde, insana varlıktan kurtulmadan sonsuzluğun izlerinin nasip olamayacağı, fenâ hâlini yaşamanın bir insanın en büyük emeli olması gerektiğini hissettirmeye çalışmıştır.

Adem Kasidesi, maddi varlıkla var olacağını düşünen her tür anlayışa, gönlünde kendi hâli ve durumuna göre fenâyı murat etmeden mutmain olmanın imkansızlı̆̆ını göstermeye çalışması yönüyle dikkate değerdir.

\section{Kaynaklar}

AKAY, Hasan (2014), Modern Türk Edebiyatında Yoklukla Gerçekleştirilen Bir Holografik Gösteri: Adem Kasidesi, Karabatak Dergisi

http://www.karabatakdergisi.com/poetika (İndirme Tarihi, 14.11.2017)

ÇETİN, Nurullah (2012), Şiir İncelemeleri, Ankara, Akçağ Yayınları

KAPLAN, Mehmet (1985), Şiir Tahlilleri 1, İstanbul: Dergâh Yayınları

KARA, Mustafa (1995), Fenâ, İslâm Ansiklopedisi, TDV Yayınları

KISAKÜREK, Necip Fazıl (2015), Çile, İstanbul, Büyük Doğu Yayınları

KOLCU, Ali İhsan (2008), Türk Şiirinde Yokluk Fikri ve Adem Kasidesi, Erzurum: SalkımSöğüt Yayınevi

PARLATIR, İsmail (1988), Tanzimat Şiiri, Büyük Türk Klâsikleri, C 8, Ankara, Ötüken Yayınları

TANPINAR, Ahmet Hamdi (1985), 19. Asır Türk Edebiyatı Tarihi, İstanbul: Çağlayan Kitabevi

YORULMAZ, Hüseyin (1996), Divan Edebiyatında Nâbi Ekolü Eski Şiirde Hikemiyât, Ankara: Akçağ Yayınları 